\title{
External validation of a classification for methylene blue magnification chromoendoscopy in premalignant gastric lesions
}

\author{
Miguel Areia, MD, Pedro Amaro, MD, Mário Dinis-Ribeiro, PhD, Maria Augusta Cipriano, MD, \\ Carol Marinho, MD, Altamiro Costa-Pereira, PhD, Carlos Lopes, PhD, Luís Moreira-Dias, PhD, \\ José Manuel Romãozinho, PhD, Hermano Gouveia, MD, Diniz Freitas, PhD, Maximino Correia Leitão, PhD \\ Coimbra, Portugal
}

Background: Conventional endoscopy has low sensitivity, specificity, and interobserver agreement for the diagnosis of gastric atrophy, intestinal metaplasia, and dysplasia. Magnification chromoendoscopy (ME) may optimize the evaluation of premalignant gastric lesions.

Objective and Design: As part of a multicenter trial, we aimed at validating a previously proposed classification for gastric methylene blue ME at a different center.

Setting, Patients, and Interventions: A sample of patients $(n=42)$ with previously diagnosed chronic atrophic gastritis with or without intestinal metaplasia underwent ME (Pentax EG-3430Z) with 1\% methylene blue by 2 endoscopists.

Main Outcome Measurements: A simplified version of a previously published ME classification (group I, group II [further divided into subgroups IIE and IIF], and group III) was used for macroscopic lesions ( $\mathrm{n}=203)$ with Sydney-Houston and Vienna classifications being used for histologic analysis $(n=479$ biopsy specimens).

Results and Limitations: Excellent reproducibility ( $w K=0.92$ [95\% CI, 0.88-0.96]) was observed for classification in groups and substantial reproducibility ( $\mathrm{wK}=0.78$ [95\% CI, 0.72-0.84]) was found for classification in subgroups. Global validity was $82 \%$ (range $78 \%-86 \%$ ), showing no false negatives (sensitivity of $100 \%$ [1/1 biopsy]) and a very low rate of false positives (specificity 99\% [297/299 biopsies]) for dysplasia detection.

Conclusions: This classification for methylene blue ME was highly reproducible and valid for the diagnosis of premalignant gastric lesions when used in a center different from that involved in its conception. Despite requiring an unconventional endoscope and a longer procedure, these results could reinforce ME as a valuable technique in the surveillance of patients at risk for gastric cancer. (Gastrointest Endosc 2008;67:1011-8.)

Gastric cancer has a high incidence worldwide and is the second most lethal neoplasm of the digestive tract. Moreover, in Portugal it ranks second in incidence of all neoplastic diseases. ${ }^{1}$ Prognosis is highly dependent on the stage at diagnosis, ${ }^{2}$ and most cases are still detected as advanced disease with an associated poor outcome.

A well-defined cascade of premalignant conditions or lesions has been proposed for the intestinal type of gastric adenocarcinoma, namely, chronic gastritis, chronic atrophic gastritis, intestinal metaplasia, and intraepithelial neoplasia (dysplasia), ${ }^{3}$ whose identification and characterization might help stratify individual risk. Unfortunately, in spite

Abbreviations: ME, magnification chromoendoscopy; NBI, narrow band imaging; Pa, proportion of agreement; $w K$, weighted Cohen $\kappa$ coefficient.

Copyright $\odot 2008$ by the American Society for Gastrointestinal Endoscopy 0016-5107/\$32.00

doi:10.1016/j.gie.2007.08.044 of the increasing ability to pinpoint superficial neoplastic lesions, atrophy and intestinal metaplasia or even minute dysplastic lesions present fairly inconspicuous endoscopic features, determining a poor interobserver agreement and low sensitivity and specificity. ${ }^{4-7}$ For this reason, diagnosis has been based mostly on biopsy specimens collected randomly or in predefined locations. ${ }^{8-11}$ This might explain the widely diverging progression rates elicited from follow-up studies, ${ }^{12,13}$ which consequently make it harder to defend screening and monitoring. ${ }^{14,15}$

\section{BACKGROUND}

New endoscopic imaging equipment and methods make it possible to detect subtle mucosal features not visible with conventional endoscopy, which might improve the identification and characterization of these premalignant 
lesions and help to target biopsy sampling. This might allow a more accurate screening, evaluation of follow-up strategies for high-risk groups, and, eventually, the diagnosis of early neoplasia suitable for endoscopic resection, ${ }^{16,17}$ with less morbidity and improved overall prognosis and survival rates.

A previous report on methylene blue magnification chromoendoscopy ${ }^{18}$ has shown good validity and reproducibility in the diagnosis of intestinal metaplasia and dysplasia. An external validation would be desirable to support further evaluation of the role that this technique may have in the secondary prevention of gastric cancer.

The aim of this study was to evaluate a classification of premalignant gastric lesions on magnification chromoendoscopy with methylene blue in a new series of patients at a different center, assessing both reproducibility and validity.

\section{METHODS}

\section{Type of study and selection of patients}

A cross-sectional study was performed that included patients with a previous diagnosis of premalignant gastric lesions (atrophic chronic gastritis, intestinal metaplasia) recruited between June 2005 and September 2006 ( $\mathrm{n}=$ 42). Patients were excluded if they had mental disorders or serious or debilitating renal, liver, or blood diseases or if they had previously undergone gastric surgery. Sixty-two percent of the patients were male; the median age was 62 years (range 39-78 years). A subgroup of 9 patients (21\%) had gastric neoplastic lesions that had previously been submitted to endoscopic resection, either by snare polypectomy or endoscopic mucosal resection. All patients gave informed consent, and the study was approved by the local ethics committee.

\section{Endoscopic procedure}

The endoscopic procedure was performed by 2 endoscopists (M.A., P.A.) at the Hospitais da Universidade de Coimbra with use of a magnification endoscope (EG3430Z, Pentax Asahi Optical, Tokyo, Japan) with a variable zoom enabling up to $105 \times$ magnification. Conscious sedation with midazolam was offered to $64 \%$, which was decided on a case-by-case basis (midazolam $2.6 \pm 2.4 \mathrm{mg}$ given intravenously, Mayne Pharma Portugal, Cascais, Portugal). All examinations were performed on an outpatient basis.

After a conventional examination, 15 to $18 \mathrm{~mL}$ of a mucolytic agent, 10\% $\mathrm{N}$-acetylcysteine (Zambon Produtos Farmacêuticos, Lisbon, Portugal), was sprayed over the gastric mucosa with a spray catheter (PW-5V-1, Olympus Optical). Two minutes later, mucus was vigorously washed out with a water pump (Aqua Jet HTS1500, Treier Endoscopie, Beromünster, Switzerland). Then $20 \mathrm{~mL}$ of 1\% methylene blue (Labesfal, Campo de Besteiros, Portugal) was sprayed over the mucosa and left in place for another 2 minutes. ${ }^{19}$ After excess dye was removed by

\section{Capsule Summary}

\section{What is already known on this topic}

- Conventional endoscopy has low sensitivity, specificity, and interobserver agreement for the diagnosis of gastric atrophy, intestinal metaplasia, and dysplasia.

\section{What this study adds to our knowledge}

- In a validation study performed in patients with chronic atrophic gastritis with or without intestinal metaplasia, magnification chromoendoscopy showed excellent reproducibility for classification in the various groups.

- Global validity was $82 \%$, there were no false-negative results, and dysplasia detection had a very low rate of false positives.

water lavage, stained and unstained mucosal areas were magnified and biopsy specimens were taken. The median time of the procedure was 25 minutes, with about 11 minutes spent on staining, 5 minutes for magnification, and 9 minutes for biopsy sampling. Patient acceptance was moderately good, although this issue was not specifically addressed. All examinations were fully completed and there were no adverse events.

For the report of the chromoendoscopy patterns, a simplified version of the classification of Dinis-Ribeiro et $\mathrm{al}^{18}$ was used. Stained and unstained areas were magnified and the following 3 groups were defined: nonmetaplastic, nondysplastic mucosa (I); metaplastic mucosa (II); and dysplastic mucosa (III). It used to be that each group had several subgroups and these were subsequently combined for simplicity and increased interobserver agreement $^{20}$ (Fig. 1).

After a theoretic explanation of the rationale for each group and subgroup of the classification was made, a learning curve was accomplished by the 2 endoscopists carrying out this study (M. A., P. A.). It consisted of a Webbased questionnaire on a random series of endoscopic film sequences. ${ }^{20}$

All analyzed mucosal areas $(n=203)$ were digitally recorded and classified by both endoscopists from Hospitais da Universidade de Coimbra (M.A., P.A.) and again by the author of the original classification at the Instituto Português de Oncologia-Porto (M.D.R.) blinded to the results of the classification at Coimbra. Each recorded and classified mucosal area was considered as a case for reproducibility and validity.

\section{Pathologic evaluation}

From the 203 selected areas a total of 479 biopsy specimens were taken (a mean of 2.3 and 11.4 specimens per area and per patient, respectively). The biopsy sampling protocol was primarily dictated by the magnification chromoendoscopy findings. Stained areas from the antrum, 

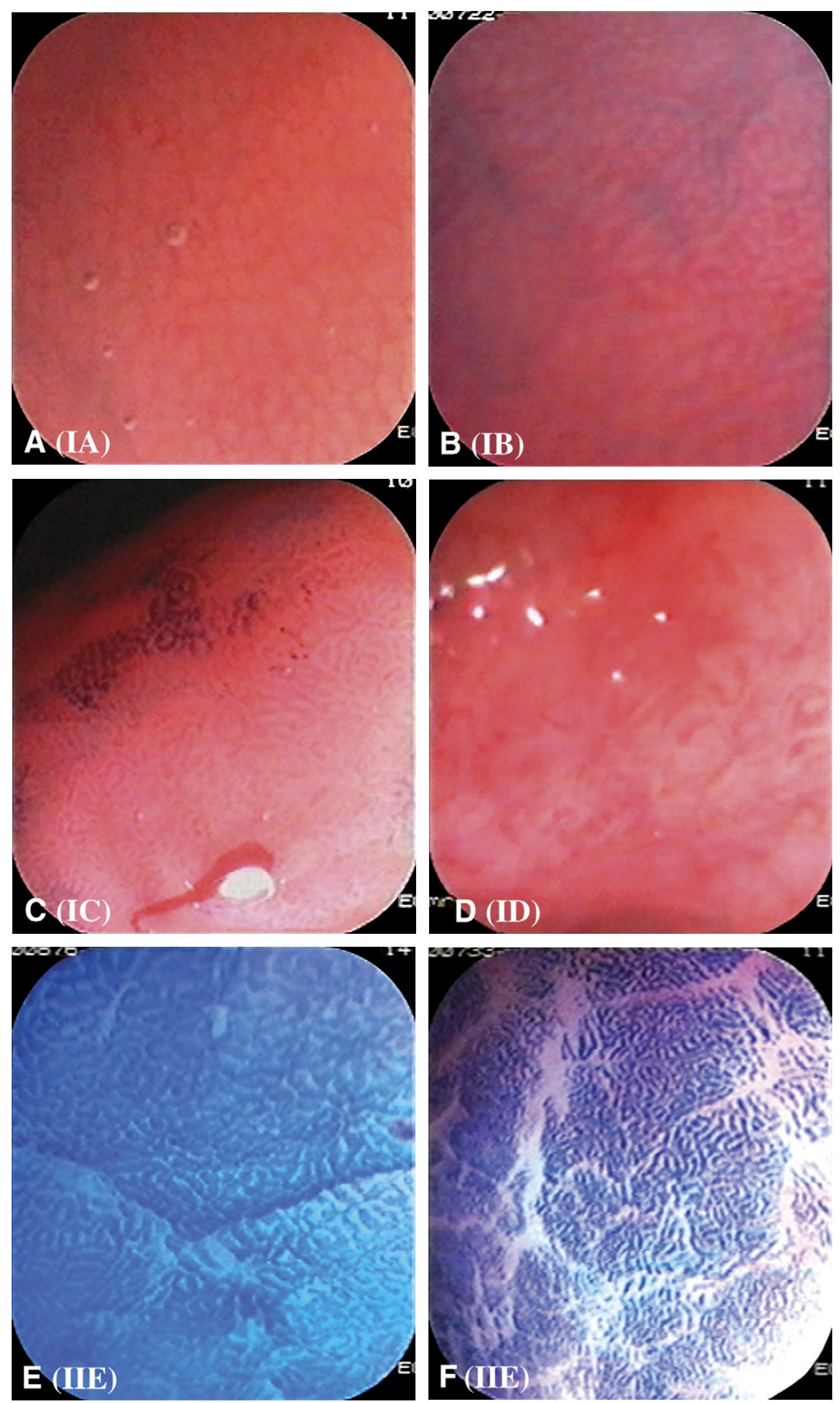

Figure 1. Magnification chromoendoscopy. Group I images (nonmetaplastic, nondysplastic mucosa; no color change, regular pattern): (A) round small pits, (B) round and tubular small pits, $(\mathbf{C})$ coarse round pits, (D) course round pits with a straight pit. Group II images (metaplastic mucosa; blue color change, regular pattern): (E and $\mathbf{F}$ ) round and tubular pits, $(\mathbf{G}$ and $\mathbf{H})$ small pits. Group III images (dysplastic mucosa; blue color change, irregular pattern): $\mathbf{I}$ and $\mathbf{J}$ 

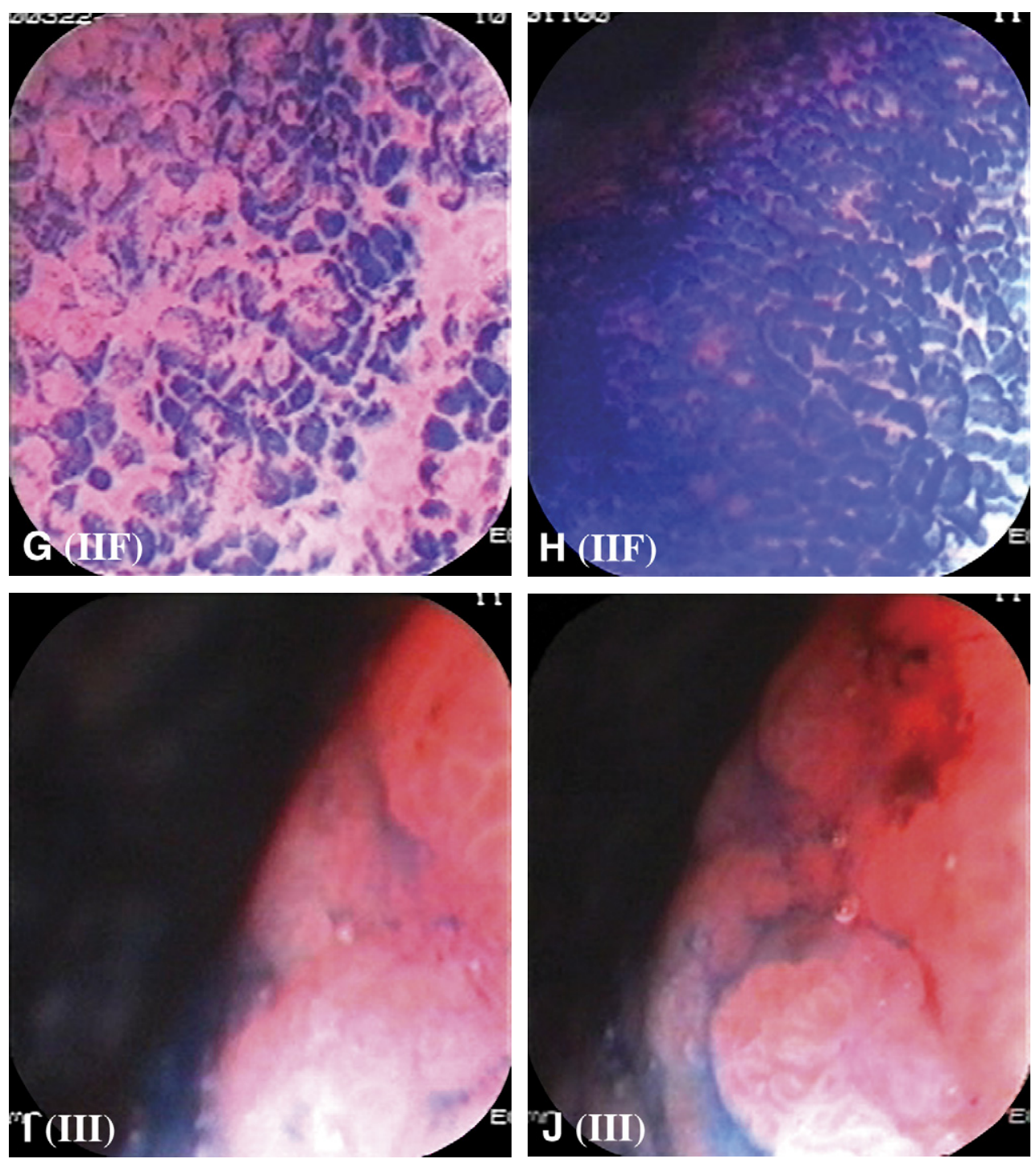

Figure 1 (continued)

incisura, and gastric body (if present) were targeted specifically; unstained areas were sampled from each of the standard locations proposed by the Sydney-Houston classification for gastritis.

Biopsy specimens were fixed in 10\% buffered formalin and embedded in paraffin wax. Histologic sections $3 \mu \mathrm{m}$ thick were cut and stained with hematoxylin-eosin and giemsa.

Gastric mucosal inflammation (mononuclear cell infiltration), activity (polymorphonuclear cell infiltration), glandular atrophy, and intestinal metaplasia were classified in accordance with the Updated Sydney System. ${ }^{21}$ Additional staining techniques were used to further characterize intestinal metaplasia: alcian blue $\mathrm{pH}$ 2.5/periodic acidic-Schiff after diastase digestion to categorize intestinal metaplasia as complete (type I) or incomplete (types II and III), and high iron-diamine/alcian blue $\mathrm{pH} 2.5$ to identify neutral, sialomucins, and sulfomucins. $^{22}$

Chronic gastritis was defined as a chronic diffuse inflammatory infiltrate with lymphocytes and plasmocytes, expanding the lamina propria and epithelium, with no atypical cellular nuclei. Atrophy was defined as the disappearance of the normal glands from a certain area of the stomach. Intestinal metaplasia was classified as type I (nonsecreting absorptive cells and sialomucinsecreting goblet cells), type II (few absorptive cells, columnar cells secreting sialomucin, and goblet cells secreting mainly sialomucin but occasionally sulfomucin), and type III (columnar cells secreting predominantly sulfomucin and goblet cells secreting sialomucin or sulphomucin). ${ }^{23,24}$

Intraepithelial neoplasia was described in 5 categories according to the revised Vienna classification. ${ }^{25}$ 
All slides $(\mathrm{n}=479)$ were reviewed by 2 pathologists (M.A.C. and C.M.) blinded to endoscopic results.

\section{Statistical analysis}

SPSS 13.0 (SPSS, Chicago, Ill) statistical software package was used for data recording and analysis. To determine the interobserver agreement, the proportion of agreement $(\mathrm{Pa})$ and weighted Cohen $\kappa$ coefficient (wK) were determined (strength of agreement considered as follows: 0.01-0.2 slight, 0.21-0.4 fair, 0.41-0.6 moderate, 0.61-0.8 substantial, and 0.81-1.0 almost perfect). ${ }^{26,27}$ For the correspondence of the endoscopic patterns with the histologic analysis, sensitivity, specificity, likelihood ratios, and area under the curve values were calculated, with the histopathologic analysis of each biopsy specimen considered the reference test.

\section{RESULTS}

\section{Reproducibility}

All stained and unstained mucosal patterns observed could be classified according to the classification, with no new pattern observed. For the interobserver agreement analysis, 203 images were evaluated and classified (Table 1).

The interobserver agreement for the classification into groups I versus II versus III was almost perfect (wK 0.92). If subgrouping of type II is considered (I versus IIE versus IIF versus III), the agreement is slightly less (wK 0.78) but still remained substantial (Table 2).

\section{Validity}

In all, 479 biopsy specimens were taken from the 203 selected mucosal areas (Table 3). Chronic atrophic gastritis was diagnosed in $76 \%$ of the patients, with complete intestinal metaplasia being present in 38\%, incomplete metaplasia in $57 \%$, and dysplasia detected in $2 \%$ of the cases. In those obtained from areas classified as type I, histologic examination revealed normal mucosa, chronic nonatrophic gastritis, or chronic atrophic gastritis without intestinal metaplasia in $86 \%$ of cases, whereas for areas assigned to type II the presence of intestinal metaplasia was seen in $81 \%$. In subtypes IIE and IIF complete intestinal metaplasia was found in $24 \%$ and $13 \%$, whereas incomplete intestinal metaplasia was present in $76 \%$ and $87 \%$, respectively ( $P=.157$ ). Of the biopsy specimens from an area classified as type III $(\mathrm{n}=3)$, 33\% exhibited intraepithelial neoplasia.

For the diagnosis of intestinal metaplasia, the classification had a diagnostic validity of $80 \%$, and for the diagnosis of intraepithelial neoplasia the diagnostic validity was $99 \%$. No false-negative results of intraepithelial neoplasia were found (Table 4).
TABLE 1. Classification in groups I, IIE, IIF, and III: interobserver agreement analysis

Instituto Português de Oncologia-Porto (M. D. R.)

\begin{tabular}{lrrrr}
\cline { 3 - 5 } $\begin{array}{l}\text { Classification (Hospitais da } \\
\text { Universidade de Coimbra) } \\
\text { (M. A., P. A.) }\end{array}$ & & & \\
\hline I & 126 & 120 & 5 & 1 \\
II & 76 & 1 & 74 & 1 \\
III & 1 & 0 & 0 & 1
\end{tabular}

TABLE 2. Reproducibility estimates for the Dinis-Ribeiro et al modified classification of magnification chromoendoscopy

$\mathrm{Pa}(95 \% \mathrm{CI})$ wK $(95 \% \mathrm{Cl})$

I vs II vs III $0.96(0.93-0.99)$ $0.92(0.86-0.98)$

TABLE 3. Histopathologic diagnosis according to magnification chromoendoscopy classification

\begin{tabular}{lccc}
$\begin{array}{l}\text { Endoscopic } \\
\text { classification (No. } \\
\text { of biopsies) }\end{array}$ & $\begin{array}{c}\text { Atrophy } \\
\text { (No. [\%]) }\end{array}$ & $\begin{array}{c}\text { Intestinal } \\
\text { metaplasia } \\
\text { (No. [\%]) }\end{array}$ & $\begin{array}{c}\text { Dysplasia } \\
\text { (No. [\%]) }\end{array}$ \\
\hline Group I $(\mathrm{n}=285)$ & $246(86)$ & $39(14)$ & 0 \\
Group II $(\mathrm{n}=165)$ & $31(19)$ & $134(81)$ & 0 \\
Group III $(\mathrm{n}=3)$ & 0 & $2(67)$ & $1(33)$ \\
\hline
\end{tabular}

\section{DISCUSSION}

Gastric cancer of the intestinal type seems to develop as a consequence of Helicobacter pylori infection interacting with host and environmental factors. ${ }^{28}$ Progression through a cascade of conditions or lesions leading to invasive neoplasia is an infrequent and unpredictable event in at-risk individuals. On the other hand, chronic atrophic gastritis and intestinal metaplasia, in spite of the wide variations of prevalence worldwide, are quite frequent findings and their clinical relevance and management are unsolved issues. ${ }^{29}$ Type III (sulfomucin) intestinal metaplasia has been associated with a significantly higher risk of progression to gastric cancer. ${ }^{14,30,31}$ However, some authors could not reproduce these results, suggesting that the extension of atrophy (or pseudopyloric metaplasia of the fundic mucosa) is the most determinant factor. ${ }^{32,33}$ One of the reasons for this discrepancy might be the inconspicuous features and the variable distribution and extent of intestinal metaplasia. In fact, morphometric 
TABLE 4. Validity estimates for magnification chromoendoscopy classification in the diagnosis of intestinal metaplasia and dysplasia

\begin{tabular}{|c|c|c|c|c|c|}
\hline Diagnosis & Se $(95 \% \mathrm{CI})$ & Sp $(95 \% \mathrm{Cl})$ & LR+ $(95 \% \mathrm{CI})$ & LR- $(95 \% \mathrm{Cl})$ & AUC $(95 \% \mathrm{Cl})$ \\
\hline Intestinal metaplasia & $0.76(0.73-0.81)$ & $0.89(0.86-0.92)$ & $6.9(4.9-156)$ & $0.27(0.2-0.36)$ & $0.80(0.77-0.84)$ \\
\hline Dysplasia & 1 & $0.99(0.98-1.00)$ & $100(25-55532)$ & 0 & $0.99(0.99-1.00)$ \\
\hline
\end{tabular}

Se, Sensitivity; Sp, specificity; $L R$, likelihood ratio; $A U C$, area under the curve.

studies have shown that intestinal metaplasia is frequently focal, which explains the lack of sensitivity of conventional endoscopy. $^{34}$

Accurate diagnosis and quantification is crucial for a more precise assessment of the natural history and prognostic significance and the evolution after interventions such as $H$ pylori eradication therapy. Furthermore, increased diagnostic accuracy and reproducibility would allow a more comprehensive understanding of the natural history of gastric cancer, helping to define more focused and cost-effective screening and surveillance strategies. ${ }^{35}$

The endoscopic evaluation of gastric mucosa has been the subject of considerable interest, and this has been recently boosted by new technologic developments and the possibility of endoscopic resection techniques. Chromoscopy with indigo carmine, a contrast agent that highlights the fine morphologic features of gastric mucosa, has been the endoscopic staining method favored, mainly for the characterization of gastric superficial neoplasia. On the other hand, magnification endoscopy has been used recently in the detection of premalignant gastric lesions. ${ }^{36,37}$

Magnification chromoendoscopy with methylene blue, a vital stain selectively taken up by intestinal absorptive columnar cells, was used by Dinis-Ribeiro et $\mathrm{al}^{18}$ to evaluate intestinal metaplasia and dysplasia. A classification was proposed on the basis of selective staining and mucosal pit pattern. This study yielded a good correlation to histologic examination and seemed reproducible and valid; in fact, for the diagnosis of intestinal metaplasia, sensitivity and specificity values were $76 \%$ and $87 \%$, respectively, whereas for dysplasia the figures were $97 \%$ and $81 \%$, respectively, with a negative predictive value of $99 \%$. Moreover, the global interobserver agreement yielded a substantial $\kappa$ value of 0.74 . However, an external validation in a different set of patients, with different endoscopists and even endoscopic equipment, was desirable to further substantiate reproducibility and validity. As far as we know, this has never been performed for other published classifications before their use in clinical practice.

Mucosal patterns similar to those reported in the original study were obtained, and all were classifiable into groups I (A to D), II (E or F), or III; no new pattern was observed. The interobserver agreement for groups I versus II versus III was nearly perfect. As for the correlation of endoscopic patterns to histologic diagnosis, $87 \%$ of the biopsy specimens from areas classified as type I revealed normal mucosa, chronic nonatrophic gastritis, or chronic atrophic gastritis, whereas in $81 \%$ of those from areas classified as type II intestinal metaplasia was present, with values of sensitivity and specificity of 0.76 (0.73-0.81) and 0.89 (0.86-0.92), respectively. These results clearly strengthen the validity and reproducibility of this classification for the diagnosis of intestinal metaplasia. When the subgrouping of group II into IIE and IIF is considered, the interobserver agreement falls, mostly in relation to subgroup IIE. Even so, global agreement between types I versus IIE versus IIF versus III would still be substantial.

When the diagnosis of intraepithelial neoplasia by methylene blue magnification chromoendoscopy is considered, limitations arise from the virtual nonexistence of dysplastic lesions in this series, probably as a result of the small number of patients, in spite of the highly selected population, including several patients with previous superficial neoplasia subjected to endoscopic mucosal resection. However, the high specificity and negative predictive values, which are not influenced by the number of true-positive findings, seem to indicate that this technique could be useful in the exclusion of intraepithelial neoplasia.

As such, this magnification chromoendoscopy classification presents a diagnostic validity of $80 \%$ and $99 \%$, respectively, for the detection of intestinal metaplasia and intraepithelial neoplasia.

In the rapidly evolving field of endoscopic imaging, new modalities are proposed and evaluated, although they are less frequently validated and hardly ever compared. So far, methylene blue chromoendoscopy has provided the best results in the detection of intestinal metaplasia. Moreover, no adverse events have been reported. Potential DNA damage is an issue but probably without consequence because of the short and episodic exposure that the procedure involves. ${ }^{38}$ On the other hand, the technique lengthens the time of the endoscopic procedure and adds to the workload of busy endoscopic departments. Likewise, tolerance of the procedure, even with sedation, may be compromised. These aspects must be taken into account when the positioning of this modality is analyzed in the face of emerging technologies such as narrow band imaging (NBI) ${ }^{39}$ computed virtual chromoendoscopy, ${ }^{40}$ or confocal endomicroscopy. ${ }^{41}$ By use of NBI with a magnifying endoscopy, Uedo et $\mathrm{a}^{39}$ recently described a distinctive endoscopic feature, a light 
blue crest on the epithelial surface that also seems to provide an accurate diagnosis of intestinal metaplasia. However, these promising new endoscopic techniques seem to be limited to providing a focal diagnosis of intestinal metaplasia. One potential advantage of methylene blue chromoendoscopy is that it landscapes the gastric mucosa, allowing an estimate of the global extent of intestinal metaplasia, either by a subjective semiquantitative evaluation, or possibly by quantitative computer image analysis. This field assessment is probably the most relevant information in relation to risk stratification and monitoring.

In conclusion, magnification chromoendoscopy with methylene blue seems to be reproducible and valid for the detection of premalignant gastric lesions, namely, intestinal metaplasia and dysplasia, with a diagnostic validity of $80 \%$ and $99 \%$, respectively, even at a different center. The high specificity and negative predictive values could justify its clinical application in the surveillance of highrisk patients.

\section{DISCLOSURE}

The authors report that there are no disclosures relevant to this publication. This study was supported by a grant from CIMAGO (Centre for Investigation on Environment, Genetics, and Oncobiology) from Coimbra University Hospital, Portugal (project 08/2005).

\section{REFERENCES}

1. GLOBOCAN 2002. Available at: http://www-dep.iarc.fr/. Accessed November 19, 2007.

2. Hundahl SA, Menck HR, Mansour EG, et al. The national cancer data base report on gastric carcinoma. Cancer 1997;80:2333-41.

3. Correa P. Human gastric carcinogenesis: a multistep and multifactorial process. First American Cancer Society award lecture on cancer epidemiology and prevention. Cancer Res 1992;52:6735-40.

4. Plummer M, Buiatti E, Lopez G, et al. Histological diagnosis of precancerous lesions of the stomach: a reliability study. Int J Epidemiol 1997;26:716-20.

5. Laine L, Cohen H, Sloane R, et al. Interobserver agreement and predictive value of endoscopic findings for $H$ pylori and gastritis in normal volunteers. Gastrointest Endosc 1995;42:420-3.

6. Fennerty MB, Emerson JC, Sampliner RE, et al. Gastric intestinal metaplasia in ethnic groups in the Southwestern United States. Cancer Epidemiol Biomarkers Prev 1992;1:293-6.

7. Sauerbruch T, Schreiber MA, Schüssler $P$, et al. Endoscopy in the diagnosis of gastritis: diagnostic value of endoscopic criteria in relation to histological diagnosis. Endoscopy 1984;16:101-4.

8. Rugge M, Farinati F, Baffa R, et al. Gastric epithelial dysplasia in the natural history of gastric cancer: a multicenter prospective follow-up study. Interdisciplinary Group on Gastric Epithelial Dysplasia. Gastroenterology 1994;107:1288-96.

9. Rugge M, Leandro G, Farinati F, et al. Gastric epithelial dysplasia: how clinicopathologic background relates to management. Cancer 1995;76:376-82.

10. Carpenter HA, Talley NJ. Gastroscopy is incomplete without biopsy: clinical relevance of distinguishing gastropathy from gastritis. Gastroenterology 1995;108:917-24.
11. Stathopoulos G, Goldberg RD, Blackstone MO. Endoscopic diagnosis of intestinal metaplasia. Gastrointest Endosc 1990;36:544-5.

12. Saraga EP, Gardiol D, Costa J. Gastric dysplasia: a histological follow-up study. Am J Surg Pathol 1987;11:788-96.

13. Yamada $H$, Ikegami $M$, Shimoda $T$, et al. Long-term follow-up of gastric adenoma/dysplasia. Endoscopy 2004;36:390-6.

14. Dinis-Ribeiro M, Lopes C, Costa-Pereira A, et al. A follow up model for patients with atrophic chronic gastritis and intestinal metaplasia. J Clin Pathol 2004;57:177-82.

15. Whiting JL, Sigurdsson A, Rowlands DC, et al. The long term results of endoscopic surveillance of premalignant gastric lesions. Gut 2002;50: 378-81.

16. Endoscopic Classification Review Group. Update on the Paris classification of superficial neoplastic lesions in the digestive tract. Endoscopy 2005;37:570-8.

17. Paris endoscopic classification of superficial neoplastic lesions: esophagus, stomach, and colon. Gastrointest Endosc 2003;58(Suppl):S3-43.

18. Dinis-Ribeiro M, Costa-Pereira A, Lopes C. Magnification chromoendoscopy for the diagnosis of gastric intestinal metaplasia and dysplasia. Gastrointest Endosc 2003;57:498-504.

19. Canto MI, Setrakian S, Willis J, et al. Methylene blue-directed biopsies improve detection of intestinal metaplasia and dysplasia in Barrett's esophagus. Gastrointest Endosc 2000;51:560-8.

20. Dinis-Ribeiro M, Cruz-Correia R, Fernandes $S$, et al. A multicenter Webbased study to assess the learning curve of a classification of magnification chromoendoscopy in gastric mucosa [abstract]. Gastrointest Endosc 2005;61:AB112.

21. Dixon MF, Genta RM, Yardley JH, et al. Classification and grading of gastritis: the updated Sydney System. International Workshop on the Histopathology of Gastritis. Am J Surg Pathol 1996;20: 1161-81.

22. Filipe MI, Lake BD. Histochemistry in pathology. Edinburgh: Churchill Livingstone; 1983.

23. Filipe MI, Jass JR. Intestinal metaplasia subtypes and cancer risk. In: Filipe MI, Jass JR, editors. Gastric carcinoma. Edinburgh: Churchill Livingstone; 1986. p. 87-115.

24. Filipe Ml, Munoz N, Matko I, et al. Intestinal metaplasia types and the risk of gastric cancer: a cohort study in Slovenia. Int J Cancer 1994;57: 324-9.

25. Dixon MF. Gastrointestinal epithelial neoplasia: Vienna revisited. Gut 2002;51:130-1.

26. Bland JM, Altman DG. Statistical methods for assessing agreement between two methods of clinical measurement. Lancet 1986;1:307-10.

27. Chien PF, Khan KS. Evaluation of a clinical test. II: assessment of validity. Br J Obstet Gynaecol 2001;108:568-72.

28. Sipponen $P$, Hyvärinen $H$, Seppälä $K$, et al. Review article: pathogenesis of the transformation from gastritis to malignancy. Aliment Pharmacol Ther 1998;12:61-71.

29. Fennerty MB. Gastric intestinal metaplasia on routine endoscopy biopsy. Gastroenterology 2003;125:586-90.

30. Silva S, Filipe MI. Intestinal metaplasia and its variants in the gastric mucosa of Portuguese subjects: a comparative analysis of biopsy and gastrectomy material. Hum Pathol 1986;17:988-95.

31. Rothery GA, Day DW. Intestinal metaplasia in endoscopic biopsy specimens of gastric mucosa. J Clin Pathol 1985;38:613-21.

32. Dore MP, Graham DY. Ulcers and gastritis. Endoscopy 2004;36:42-7.

33. Xia HH, Kalantar JS, Talley NJ, et al. Antral-type mucosa in the gastric incisura, body, and fundus (antralization): a link between Helicobacter pylori infection and intestinal metaplasia? Am J Gastroenterol 2000;95:114-21.

34. El-Zimaity HM, Ota H, Graham DY, et al. Patterns of gastric atrophy in intestinal type gastric carcinoma. Cancer 2002;94:1428-36.

35. Dinis-Ribeiro M, Costa-Pereira A, Lopes C, et al. Feasibility and costeffectiveness of using magnification chromoendoscopy and pepsinogen serum levels for the follow-up of patients with atrophic chronic gastritis and intestinal metaplasia. J Gastroenterol Hepatol 2007;22: 1594-604. 
36. Yang JM, Chen L, Fan YL, et al. Endoscopic patterns of gastric mucosa and its clinicopathological significance. World J Gastroenterol 2003;9: 2552-6.

37. Tajiri $H$, Doi $T$, Endo $H$, et al. Routine endoscopy using a magnifying endoscope for gastric cancer diagnosis. Endoscopy 2002;34:772-7.

38. Olliver JR, Wild CP, Sahay P, et al. Chromoendoscopy with methylene blue and associated DNA damage in Barrett's oesophagus. Lancet 2003;362:373-4.

39. Uedo $\mathrm{N}$, Ishihara $\mathrm{R}$, lishi $\mathrm{H}$, et al. A new method of diagnosing gastric intestinal metaplasia: narrow-band imaging with magnifying endoscopy. Endoscopy 2006;38:819-24.

40. Pohl J, May A, Rabenstein T, et al. Computed virtual chromoendoscopy: a new tool for enhancing tissue surface structures. Endoscopy 2007;39:80-3.

41. Hoffman A, Goetz M, Vieth $M$, et al. Confocal laser endomicroscopy: technical status and current indications. Endoscopy 2006;38:1275-83.
Received April 18, 2007. Accepted August 20, 2007.

Current affiliations: Gastroenterology Department (M.A., P.A., J.M.R., H.G., D.F., M.C.L.), Pathology Department (M.A.C., C.M.), CIMAGO/Centre for Investigation on Environment, Genetics, and Oncobiology, Faculty of Medicine (M.A., P.A., J.M.R., D.F., M.C.L.), Coimbra University Hospital, Coimbra, Portugal, Gastroenterology Department (M.D.-R., L.M.-D.), Pathology Department (C.L.), Portuguese Oncology Institute, Porto, Portugal, CINTESIS/Department of Biostatistics and Medical Informatics, Faculty of Medicine (M.D.-R., A.C.-P.), Porto University, Porto, Portugal.

Presented as an abstract in UEGW, October 21-25, 2006, Endoscopy 2006;38(2 Suppl):A217.

Reprint requests: Miguel Areia, MD, Gastroenterology Department, Coimbra University Hospital, Praceta Mota Pinto, 3000-075 Coimbra, Portugal.

Access to Gastrointestinal Endoscopy Online is reserved for all subscribers!

Full-text access to Gastrointestinal Endoscopy Online is available for all subscribers. ASGE MEMBER SUBSCRIBERS: To activate your individual online subscription, please visit http://www.asge.org and follow the instructions. NONMEMBER SUBSCRIBERS: To activate your individual online subscription, please visit http://www. giejournal.org and follow the prompts to activate your online access. To activate your account, you will need your subscriber account/membership number, which you can find on your mailing label (note: the number of digits in your subscriber account number varies from 6 to 10 digits). See the example below in which the subscriber account number has been circled:

Sample mailing label

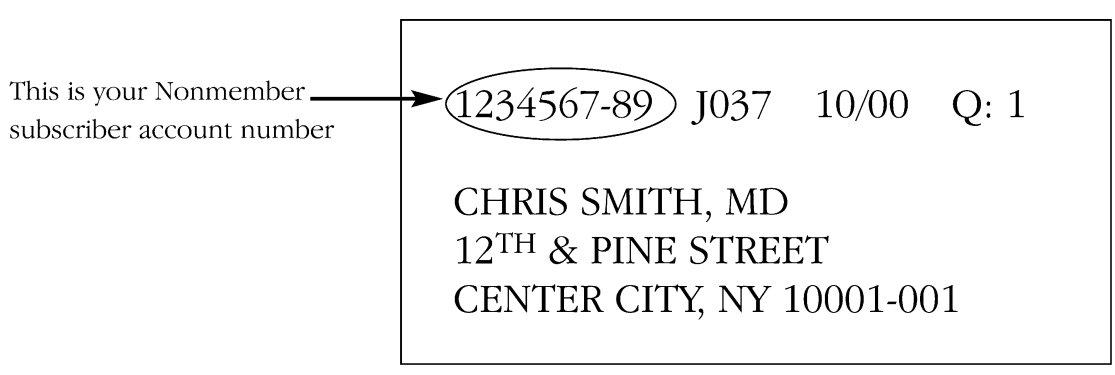

Personal subscriptions to Gastrointestinal Endoscopy Online are for individual use only and may not be transferred. Use of Gastrointestinal Endoscopy

Online is subject to agreement to the terms and conditions as indicated online. 